\title{
Cognitive requirements for primary care providers during the referral process: Information needed from and interactions with an electronic health record
} system

April Savoy, PhD, a,b,c,d april.savoy@va.gov

Laura Militello, M.A., ${ }^{\mathrm{I} . m i l i t e l l o @ a p p l i e d d e c i s i o n s c i e n c e . c o m ~}$

Julie Diiulio, ${ }^{\mathrm{e}}$ j.diiulio@applieddecisionscience.com

Amanda M. Midboe, PhD, f,g ' amanda.midboe@va.gov

Michael Weiner, MD, MPH, ${ }^{\text {a,c,d }}$ mweiner@iu.edu

Hamed Abbaszadegan, MD, h,i Hamed.Abbaszadegan@va.gov

Jennifer Herout, PhD jennifer.Herout@va.gov

${ }^{a}$ Center for Health Information and Communication, U.S. Department of Veterans Affairs, Veterans Health Administration, Health Services Research and Development Service CIN 13-416, Richard L. Roudebush VA Medical Center, 1481 W 10th St, Indianapolis, IN 46202

${ }^{b}$ Purdue School of Engineering and Technology, IUPUI, 799 W Michigan St, Indianapolis, IN 46202

'Indiana University Center for Health Services and Outcomes Research, 1101 W. 10 ${ }^{\text {th }}$ St., Indianapolis, IN 46202

${ }^{d}$ Regenstrief Institute, Inc. 1101 W. $10^{\text {th }}$ St., Indianapolis, IN 46202

eApplied Decision Science, LLC, 1776 Mentor Ave \# 424, Cincinnati, OH 45212

${ }^{\mathrm{f} C e n t e r ~ f o r ~ I n n o v a t i o n ~ t o ~ I m p l e m e n t a t i o n, ~ V A ~ P a l o ~ A l t o ~ H e a l t h ~ C a r e ~ S y s t e m, ~} 795$ Willow Road (152-MPD)

Menlo Park, California, 94025

hPhoenix VA Health Care System, 650 E Indian School Rd, Phoenix, AZ 85012

'University of Arizona College of Medicine, 475 N 5th St, Phoenix, AZ 85004

${ }^{\mathrm{j} H u m a n}$ Factors Engineering, Health Informatics, Office of Health Informatics and Analytics, Veterans Health Administration, 810 Vermont Ave NW, Washington, DC 20571

\section{Corresponding author:}

April Savoy, PhD

Richard L. Roudebush Veterans Affairs Medical Center

1481 West $10^{\text {th }}$ St. $(11 \mathrm{H})$

Indianapolis, IN 46202

E: april.savoy@va.gov

P: 317-988-2437

\section{Highlights}

- Throughout the referral process, referring physicians have high cognitive demand.

- Our cognitive framework identifies referring physicians' information needs.

- EHR designs create cognitive challenges when ordering, tracking, and reviewing referrals.

- Referring physicians' goals, tasks, decisions, and information needs can inform EHR (re)design. 


\title{
Cognitive requirements for primary care providers during the referral process: Information needed from and interactions with an electronic health record system
}

\begin{abstract}
Objectives: This study sought to identify and describe the cognitive requirements and associated information needs of referring primary care providers (PCPs) during the referral process as well as characterize referring PCPs' experiences with current health information technology.

Materials and Methods: We interviewed 62 referring PCPs. Our four-member analysis team used hierarchical task analysis to construct a goal-directed hierarchy. We utilized extensions of the task analysis to describe PCPs' common experiences with health information technologies throughout the referral process.
\end{abstract}

Results: The resultant goal hierarchy includes one main goal (Referral for Additional Care), two sub-goals (Assess Patient's Condition and Manage Referrals), and four major tasks with respective decisions (What consultation is warranted; What information should I provide; What additional action is needed; and How to integrate specialists' findings). Approximately 22 information needs were commonly identified and PCPs described their use of various sources - other PCPs, electronic health records, chat software, and paper- to satisfy those information needs.

Conclusion: Cognitive demand for referring PCPs is high throughout the referral process. They have to search, identify, compose, track, and integrate information across multiple screens, systems, and people. Existing interfaces do not adequately support the communication, information exchange, or care coordination related to the referral process. Results from this study provide an important foundation for developing patient-centered displays that support PCPs' decision-making process and reduce cognitive challenges.

\section{Abbreviations: \\ PCPs: Primary Care Providers \\ EHR: Electronic Health Record \\ HIT: Health Information Technology \\ VA: U.S. Department of Veterans Affairs}

Keywords: referrals, health information technology, information needs, outpatient care, cognitive demand, referral communication 


\section{Introduction}

Poor care coordination of specialty referrals can increase delays in diagnosis and treatment, as well as physician workload and risks to patient safety. Although referrals for specialty consultations are a core clinical process, they are prone to coordination and communication breakdowns. Both sociological and technological aspects of this process make referrals prone to these breakdowns before and after the consultation causing long wait times to specialty care, delayed treatment, and medical errors[1, 2]. From one analysis of a national malpractice claims database, these types of breakdowns resulted in \$1.7 billion in losses and adverse clinical outcomes, including death [3]. With the increase in the number of ambulatory care visits resulting in specialty referrals, it is important to improve care coordination of specialty referrals [4].

Through specialty referrals, primary care providers (PCPs) seek advice, request procedures, and coordinate evaluation and management of their patients [5]. Referrals for specialty consultations require complex care coordination throughout a multi-step process that involves PCPs and specialists, potentially from disparate healthcare organizations. Successful coordination of referrals requires effective, timely information sharing to facilitate communication and transfer of patient care responsibilities. However, communication and health information exchange during the referral process are not adequately supported by electronic health record (EHR) systems [6].

An improved understanding of PCPs' cognitive requirements and how they change across the various steps of the referral process is needed. Limited EHR system functionality and integration into clinical workflow contribute to increases in physician workload, medical errors, and patient safety risks [7-9]. To develop tools that promote effective care coordination, designers must understand who needs the information, when they need it, what information they need, and how it can be made available [6]. Previous cognitive studies related to consultations and referrals have focused on the hidden complexities of information flow [10], conducted heuristic evaluations of electronic consultation order forms [11], identified cognitive challenges for consultation orders [12], and translated cognitive requirements for consultation orders into design guidelines for electronic forms [13]. Yet, research is needed to understand the cognitive challenges and requirements for referring PCPs throughout the entire referral process.

Thus, our goal was to assess the PCPs' cognitive processing throughout the entire referral process. In this study, we conducted a hierarchical task analysis to create a cognitive framework, identify 
information needs, and describe PCPs' experience with health information technology (HIT). We focus on referring primary care providers' goals, tasks, and information needs as they work with an EHR to order consultations in the context of the referral process. This study elucidates problems with HIT and provides a foundation for developing patient-centered displays that support PCPs' decision-making process.

\section{Materials and Methods}

\subsection{Overview}

Focused on referring PCPs, we used hierarchical task analysis and its extensions to identify information needs and describe PCPs' experiences with HIT throughout the referral process[14, 15] (see Figure 1). We began with PCP cognitive interviews to develop a goal hierarchy. With this goal hierarchy, contextual inquiry interviews were conducted to identify specific information and technical support needs for PCPs' goals and decisions. A card-sorting exercise was then used to validate our initial understanding of PCPs' goals and information needs. This phased data collection and analytical approach enabled a representation of PCPs' interaction with the system while describing their information needs and decision-making process in narrative form.

\subsection{Participant Recruitment}

We recruited convenience samples of participants, who were stratified across three urban, geographically-dispersed U.S. Department of Veterans Affairs (VA) medical centers. PCPs, who have experienced the referral process, were invited to participate via email. Participation was limited to only one instance of knowledge elicitation. For each method, we determined the target sample size (10-12 participants) based on data saturation recommendations $[16,17]$.

\subsection{Data Collection}

\subsubsection{Cognitive Interviews}

Interviewers worked in pairs conducting in-person interviews lasting approximately 30 to 60 minutes. Six questions served as the foundation (Figure 2). Interviewers followed up with probing questions tailored to the role and experience of each interviewee.

\subsubsection{Contextual Inquiry}


Contextual inquiry interviews focused on information needs that support decision-making for steps in the referral process $[18,19]$. Contextual inquiry was used to gain a deeper understanding of specific information requirements and interactions with information sources to assess gaps.

Participants were shown the goal hierarchy and asked to modify, if needed. Afterwards, participants walked through the information needed to make the decisions associated with each task. Participants logged into the EHR to demonstrate how and where they found needed information. They also provided insights to challenges and strategies that are often encountered across various types of referrals.

\subsubsection{Card Sort}

A card-sorting exercise was used to validate the goal hierarchy and information needs [20, 21]. Participants were presented with the goal hierarchy. They were then presented with cards representing tasks, information needs, and sources. They sorted the cards according to associations with each task and decision. Blank cards were available so participants could add tasks, information needs, and sources that had not been identified previously. Each task and card classification was documented for analysis.

\subsection{Analyses}

For each phase of analysis, audio recordings of interviews were transcribed. Transcripts were deidentified to protect participants' privacy. Four team members conducted the analysis.

For the hierarchical task analysis of the cognitive interview data, we used an iterative, consensus-based approach to create codes corresponding to key cognitive tasks of referral processes (e.g., referral, triage, and tracking), supportive technology used, and contextual factors (e.g., staffing, roles, and policies). Researchers worked in pairs, coding transcripts using NVivo 10 (QRS International, Melbourne, Australia) [22] and resolving discrepancies by consensus. In parallel, the study team reviewed existing literature to integrate findings related to referring PCPs' goals and decisions during the referral process. This provided context for interpreting interview data and developing the initial goal hierarchy. The study was approved by the VA's Central Institutional Review Board.

The contextual inquiry and card sort data were deductively analyzed to identify specific information needs related to tasks and decisions from the goal hierarchy. We used an iterative, consensus-based approach to create codes corresponding to information needs, technology used, strategies, and 
challenges. Researchers worked in pairs for the first round of coding using spreadsheets to accommodate distributed analysis. Discrepancies were resolved in a consensus meeting.

\section{Results}

\subsection{Participants}

For cognitive interviews, data saturation was met with 36 PCPs. Participants spent 0 to 55 hours per week in clinic. Average time in clinic was 30 hours per week $(S D=7.4)$. Their clinical experience ranged from 1.5 to 40 years, averaging 19 years $(S D=11)$. Participants' experience in the current healthcare system ranged from 4 months to 29 years, averaging 8 years $(S D=13)$. Twenty-two women and 14 men participated.

For contextual inquiry and card sort interviews, data saturation was achieved with 26 additional PCPs. Participants spent from 3 to 55 hours per week in clinic. Average time in clinic was 32 hours per week $(S D=15)$, with approximately 5.6 hours, self-reported, devoted to referral management processes. Their clinical experience ranged from 1 to 41 years, averaging 18 years $(S D=11)$. Participants' experience in the current healthcare system ranged from .5 to 41 years, averaging 9.8 years (SD $=9.7$ ). Twelve women and 14 men participated.

\subsection{Goal Hierarchy}

From the hierarchical task analysis of cognitive interviews, we developed a descriptive, goal hierarchy task analysis model comprised of one main goal, two sub-goals, four key-tasks, and four decisions related to the referral process (see Figure 3). This model illustrates the main goal, Referral for Additional Care, which has been decomposed into two sub-goals, Assess Patient Condition and Manage Referrals. These sub-goals serve as two major categories of cognitive needs. Below the sub-goals, we illustrate associated, major tasks and decisions.

\subsubsection{Sub-Goal 1.0: Assess Patient's Condition}

Decision 1.1: What consultation is warranted? Related to the first sub-goal (Table 1), PCPs indicated that they routinely review patient information before and during the encounter, and discuss current status and patient priorities with patients during the encounter. This review of current and recent information helps PCPs to re-orient to a specific patient and prioritize issues to address during the medical encounter. Identifying potentially valuable referrals is one byproduct of this review process. Participants reported two primary categories of information that trigger a referral order. The first is noteworthy 
information since the last visit, obtained from the EHR, and the second is information obtained from discussion with the patient during visit.

"It [motivation for referral] could be anything. It could be patient symptom. It could be that an abnormal x-ray, an abnormal lab result. There are a number of things." - [participant]

\subsubsection{Sub-Goal 2.0: Referral Management}

Decision 2.1: What information should I provide? For some, especially less-experienced PCPs, determining which specialty clinic is most appropriate may require considerable information searching and gathering (Table 1). Participants reported a lack of support in determining which specialty clinic is most appropriate. A related issue is finding the correct electronic referral request form. To find this form, the referrer must know what name is used in the EHR's referral menu.

"I think that Gl is a hard referral to put in because there are multiple titles of GI referrals, and they're not all in the same place. Some of them are under GI, and some of them are under gastro. I mean that's annoying. I'll say as a new person transferring here that I have a hard time finding referrals. They're not where you think that they're going to be." - [participant]

Table 1. Specific Information Needs and Card Sort Results

\begin{tabular}{|c|c|c|c|}
\hline Tasks - Decisions & Information Needs & Information Components & $\begin{array}{l}\text { Participant } \\
\text { Agreement } \\
\quad(\%)\end{array}$ \\
\hline \multirow{12}{*}{$\begin{array}{l}\text { Review clinical } \\
\text { information - What } \\
\text { consultation is } \\
\text { warranted? }\end{array}$} & \multirow{8}{*}{$\begin{array}{l}\text { Progress/Events Since Last } \\
\text { Visit }\end{array}$} & Recent Progress Note & 88 \\
\hline & & $\begin{array}{l}\text { Historical Data (i.e., labs, } \\
\text { meds, problem list) }\end{array}$ & 65 \\
\hline & & Imaging & 54 \\
\hline & & Consults & 50 \\
\hline & & $\begin{array}{l}\text { Previous Procedures or } \\
\text { Interventions }\end{array}$ & 38 \\
\hline & & Procedures & 38 \\
\hline & & Labs & 38 \\
\hline & & Acute Events & 35 \\
\hline & \multirow{4}{*}{$\begin{array}{l}\text { Clinical } \\
\text { Information/Current Visit }\end{array}$} & New Symptoms & 62 \\
\hline & & Patient Request & 50 \\
\hline & & Physical Exam & 38 \\
\hline & & Nurse Notes & 35 \\
\hline \multirow{2}{*}{$\begin{array}{l}\text { Create Consult } \\
\text { Orders - What }\end{array}$} & Specialty Clinic Options & Specialty Clinic Services & 38 \\
\hline & $\begin{array}{l}\text { Consult Template Form } \\
\text { Name }\end{array}$ & $\begin{array}{l}\text { Name of Specialty Clinic } \\
\text { Template }\end{array}$ & 38 \\
\hline
\end{tabular}




\begin{tabular}{|l|l|l|c|}
\hline \multirow{2}{*}{$\begin{array}{l}\text { information should I } \\
\text { provide? }\end{array}$} & $\begin{array}{l}\text { Specialty Clinic } \\
\text { Requirements }\end{array}$ & $\begin{array}{l}\text { Consult Template-Specific } \\
\text { Information }\end{array}$ & 65 \\
\cline { 3 - 4 } & $\begin{array}{l}\text { Specialty-Specific } \\
\text { Prerequisites }\end{array}$ & 58 \\
\cline { 2 - 4 } & $\begin{array}{l}\text { Specialty Clinic } \\
\text { Administrative } \\
\text { Information }\end{array}$ & $\begin{array}{l}\text { Specialty Clinic Phone } \\
\text { Numbers }\end{array}$ & 31 \\
\hline $\begin{array}{l}\text { Track Consults - } \\
\text { What additional } \\
\text { action(s) is needed? }\end{array}$ & Consultation Status & Reason for Cancellation & 65 \\
\cline { 3 - 4 } & & Status (e.g. Cancelled) & 58 \\
\cline { 3 - 4 } $\begin{array}{l}\text { Review Consult Notes } \\
\text { - How to integrate } \\
\text { specialists' findings? }\end{array}$ & $\begin{array}{l}\text { Findings and } \\
\text { Recommendations }\end{array}$ & $\begin{array}{l}\text { Findings and } \\
\text { Recommendations from } \\
\text { Internal Consults }\end{array}$ & 46 \\
\cline { 3 - 4 } & & $\begin{array}{l}\text { Findings and } \\
\text { Recommendations from } \\
\text { External Consults }\end{array}$ & 31 \\
\hline
\end{tabular}

After a specialty clinic has been identified and a referral template form located, a referrer must locate and provide key information to the specialty clinic. Referrers must anticipate what information the specialty clinic will need to triage and care for each patient appropriately. The interface functionality is problematic, as illustrated below.

"If you're in the middle of a referral and it starts asking for specific pieces of data, then you've got to get out of here, and you've got to go find that information. The problem with that is when you get out of here, you're out of here. So it's not easy to navigate back and forth from an active referral menu to look at labs, reports, and so forth. Once I get into this, I can't get to these other tabs."

Some specialty clinics require specific prerequisites before they will accept a referral. In many cases, the prerequisite tests required are displayed on the referral template form, but these are not always current.

Decision 2.2: What additional action is needed? Participants reported broad variability in tracking strategies. However, most PCPs reported that they do not formally "track" their referral requests and rely on view alerts (on-screen listing of notifications to be reviewed) to notify them of a change in the status of referral requests (Table 1). Challenges of the alerts include their quantity-sometimes hundreds per day-and the frequent need to take additional action upon seeing an alert. Other participants print orders and use the printed documents as a reminder to check consultation orders in a 
week. Key information needed includes the status (e.g. pending, scheduled, and cancelled) of internal and external (cross-institutional) referrals.

Decision 2.3: How to integrate specialists' findings? To integrate recommendations and findings from the referral into the patient's holistic care plan, PCPs review the report from the specialist (Table 1). In the EHR, the location of the specialist report varies.

"... [It] would be nicer if the Notes tab was further segregated into PCP notes and non-PCP notes. The reason being. See, this guy has 1800 notes. There are some that have 3500, and God help us if we had to go in and look up a note not in the top couple of hundred because it may take 3 minutes to load all of that stuff in. Then, you have to go dig through and figure out where it is."

The referrer needs to know whether the clinical issue was resolved, and whether the patient understands the findings and the next steps.

Table 1 denotes participant agreement among information needs resulting from the card sort. The information needs were further decomposed to identify specific information components. Participant agreement percentages were calculated based on the number of participants that identified the specific component as needed divided by total number of participants.

\section{Discussion}

The referring PCPs' information needs are goal-directed and were presented with a goal-directed hierarchy model. This model enabled the organization and analysis of information needs in a structured manner highlighting cognitive requirements, facilitating rapid uptake and discussion. To present a concise framework that explains how the information perceived has meaning to referring PCPs, we deemphasized the order or explicit steps of information retrieval. As a result, this cognitive framework signifies the information needs rather than the complete description of the environmental organizational contextual factors, which is highly variable. Furthermore, technological support to fulfill information needs for the goals, tasks, and major decision points was considered.

Existing technical support for each decision point may have a negative impact on PCPs' cognitive demand. Table 2 denotes the most salient challenges for referring PCPs during the referral process. 
Table 2. Summary table

\begin{tabular}{|c|c|}
\hline Tasks - Decisions & Challenges \\
\hline \multirow{2}{*}{$\begin{array}{l}\text { Review Patient } \\
\text { Information - } \\
\text { What consultation } \\
\text { is warranted? }\end{array}$} & $\begin{array}{l}\text { - Results of previous consults are difficult to find. To manage this challenge, } \\
\text { PCPs developed search strategies that often include checking multiple tabs (i.e., } \\
\text { consults tab, reports tab, notes tab) for potentially relevant information. }\end{array}$ \\
\hline & $\begin{array}{l}\text { - Information from external events is not integrated. Strategies to manage this } \\
\text { challenge included asking the patient about previous procedures and findings, } \\
\text { and asking the patient to hand-deliver records from outside the current } \\
\text { healthcare system. }\end{array}$ \\
\hline \multirow{6}{*}{$\begin{array}{l}\text { Create } \\
\text { Consultation } \\
\text { Orders - } \\
\text { What information } \\
\text { should I provide? }\end{array}$} & $\begin{array}{l}\text { - Unclear which specialties handle particular consults. If the referrer was unsure } \\
\text { which clinic handles a specific procedure, s/he would often resort to trial and } \\
\text { error, or asked colleagues for recommendations about where to start. }\end{array}$ \\
\hline & $\begin{array}{l}\text { - Poor menu organization. Some interviewees reported that the consults menu } \\
\text { organization and naming structure were difficult to predict and navigate. Some } \\
\text { described heuristics -- such as searching the surgery submenus - as being forced } \\
\text { to browse menus that are rarely used for consultations. Others reported, when } \\
\text { they were new to the organization, they spent time exploring the consultations } \\
\text { search menu to try to understand the underlying organizational structure. }\end{array}$ \\
\hline & $\begin{array}{l}\text { - Cannot leave template to find needed information. When completing the } \\
\text { consults template form, the referrer may be asked to provide a specific test } \\
\text { result that is already stored elsewhere in the medical record. However, if the } \\
\text { referrer leaves the consults form to check the Labs tab, all data previously } \\
\text { entered in the template form will be lost. Some reported that they will provide } \\
\text { placeholder text and then proceed to the review order page where they can cut } \\
\text { and paste information from other tabs. For forms that are used frequently, some } \\
\text { PCPs would look up the required information and jot it down (or remember it) } \\
\text { before entering the consult template form. }\end{array}$ \\
\hline & $\begin{array}{l}\text { - Must re-enter information already stored in the EHR. Some found the need to } \\
\text { re-enter information already stored in the EHR to be tedious and consider it } \\
\text { unnecessary. For some, this suggests that from an organizational perspective, } \\
\text { specialist time is more valued that primary care time. Some expressed } \\
\text { resentment that they are asked to use a cumbersome form to re-enter } \\
\text { information that is already available to the specialist in the medical record. }\end{array}$ \\
\hline & $\begin{array}{l}\text { - Specialists' needs are unclear. Although some consultation template forms } \\
\text { make required tests and procedures very clear, some do not. For those in which } \\
\text { the prerequisites are not well articulated, PCPs reported frustration as they learn } \\
\text { what is actually required via the burdensome process of reviewing and } \\
\text { resubmitting rejected consult requests. In many cases, the most important field - } \\
\text { - the reason for the consult -- is not required. On some consult template forms, } \\
\text { there were redundant date fields and scheduling date options, creating } \\
\text { confusion about which date fields are used for what purpose. }\end{array}$ \\
\hline & $\begin{array}{l}\text { - Onerous forms and usability issues. Consult template forms are not } \\
\text { standardized. While some are straightforward and easy to use, others are } \\
\text { onerous and difficult to use. Attributes that make a form onerous include }\end{array}$ \\
\hline
\end{tabular}




\begin{tabular}{|c|c|}
\hline & $\begin{array}{l}\text { unnecessary questions and prerequisites, the use of checkboxes to communicate } \\
\text { information that would be more easily and accurately conveyed in a free-text } \\
\text { field, and long forms that require extensive reading and many clicks. Examples of } \\
\text { usability issues include the need to enter the clinically indicated date manually } \\
\text { for each request, though for most of the consults, which have no medical } \\
\text { urgency, the clinically indicated date will be "next available appointment". }\end{array}$ \\
\hline & $\begin{array}{l}\text { - Prerequisites may include additional consult orders with time dependencies. } \\
\text { For example, an orthopedics consult template form may require that the patient } \\
\text { obtain an MRI, an x-ray, and six weeks of physical therapy before the } \\
\text { orthopedics consult request will be considered. Therefore, the referrer must } \\
\text { order the necessary prerequisite consults, and then remember to order the } \\
\text { orthopedics consult when the results from the prerequisites are available. There } \\
\text { is no technical support to track this type of time dependency. }\end{array}$ \\
\hline \multirow[t]{4}{*}{$\begin{array}{l}\text { Track Consults - } \\
\text { What additional } \\
\text { action }(s) \text { is } \\
\text { needed? }\end{array}$} & $\begin{array}{l}\text { - Consult status unknown. Many found it difficult to track the status of a specific } \\
\text { consult after it has been ordered. Some reported that they are most likely to } \\
\text { discover whether a consult occurred and whether follow-up actions are required } \\
\text { at the time of the patient's next appointment. While reviewing the medical } \\
\text { record in preparation for seeing the patient, many PCPs routinely check on } \\
\text { consults previously ordered. This is an adequate system for routine } \\
\text { consultations, but the PCP may be unaware when a problem arises and a consult } \\
\text { is delayed or does not occur as expected. Some PCPs maintain a separate } \\
\text { tracking system for consults with high priority (i.e., potential cancer diagnoses, } \\
\text { patients who are particularly vulnerable) in the form of a paper journal, } \\
\text { spreadsheet, or a series of calendar reminders. }\end{array}$ \\
\hline & $\begin{array}{l}\text { - View alerts are an inadequate tracking tool. Many reported limitations of view } \\
\text { alerts or notifications feature for tracking consults. A common complaint was } \\
\text { that an individual PCP receives so many alerts each day, that it is difficult to find } \\
\text { the important notifications in the deluge of trivial ones (i.e., a patient picked up } \\
\text { a cane). Managing the long list of view alerts is very time-consuming. Some find } \\
\text { the rules for saving view alerts to be confusing. Current functionality } \\
\text { automatically deletes each view alert after it has been viewed. Thus, if a PCP is } \\
\text { distracted and clicks away from the view alert, the content is lost and cannot be } \\
\text { retrieved. It is possible to "Renew" a view alert, but some interviewees reported } \\
\text { that they are unaware of this capability. Some report that the view alert feature } \\
\text { is unreliable. }\end{array}$ \\
\hline & $\begin{array}{l}\text { - Individual consults may be cancelled multiple times. Some reported that an } \\
\text { individual consult may be declined } 3 \text { or } 4 \text { times by the same specialty clinic. This } \\
\text { dysfunctional loop leads to delays in care for the patient and frustration for the } \\
\text { PCP. }\end{array}$ \\
\hline & $\begin{array}{l}\text { - Correct procedure to resubmit consults is unclear and difficult. Some } \\
\text { interviewees reported confusion about when a rejected consult can be } \\
\text { resubmitted and when it must be completely re-entered. Some reported } \\
\text { confusion about how a rejected consult request affects the } 30 \text {-day target for } \\
\text { completing the consult. Does the } 30 \text {-day countdown restart in some cases? Does } \\
\text { the } 30 \text {-day countdown always begin with the original consult request and } \\
\text { continue until the consultation is complete, regardless resubmissions that may } \\
\text { occur along the way? }\end{array}$ \\
\hline
\end{tabular}




\begin{tabular}{|c|c|}
\hline \multirow[t]{2}{*}{$\begin{array}{l}\text { Review Consult } \\
\text { Notes - } \\
\text { How to integrate } \\
\text { specialists' } \\
\text { findings? }\end{array}$} & $\begin{array}{l}\text { - Location of consultant's findings is inconsistent. Participants reported that } \\
\text { they may find the report from the specialist on the Consults Tab or on the } \\
\text { Reports Tab. Relevant information may be on the Notes Tab, as well. Within the } \\
\text { Notes Tab, the list of notes for that particular patient may be lengthy and notes } \\
\text { may have similar titles, making it difficult to quickly scan the list. Finding the } \\
\text { specialist note in the list can be challenging. }\end{array}$ \\
\hline & $\begin{array}{l}\text { - Notes are cumbersome and lengthy. After locating the relevant note or report } \\
\text { from the specialist, the format often makes it difficult to obtain needed } \\
\text { information quickly ("at-a-glance"). Specialist reports often add the newest } \\
\text { information at the very bottom of the document, requiring scrolling to find the } \\
\text { most important information. Notes format is somewhat idiosyncratic, so the PCP } \\
\text { must search to find the current findings and recommendations. }\end{array}$ \\
\hline
\end{tabular}

The first sub-goal, Assess Patient's Condition, is often omitted from referral discussions. However, our analysis denotes that it should be included. Determining what triggers a referral is important to understanding the PCPs' mental model and decision-making process. This step is significant because delays in access to specialty care stems from it. Determining if a referral is needed or which referral is needed starts the entire process. It is also linked to what information will be transferred, and frames the subsequent communications.

Most information needs were related to the Create Referral Order task. Addressing the requirements specified in referral order templates were difficult due to limitations with EHR interaction. Many PCPs mentioned that selection of the proper template involved trial and error. There are no guiding indicators or standard nomenclature across or within specialty clinics. These templates have many usability problems [11]. Participants described many templates as long and difficult to complete. In addition, information required by the templates was located in various different places in the EHR. PCPs had difficulty searching, remembering, and entering the data, with no option to save partially completed templates while searching for additional information.

For tracking and monitoring referrals, missing information was the main issue. There is no adequate technology support for tracking status of referrals. PCPs' main concern was to be alerted when additional follow-up actions were needed [23]. This is where major communication breakdowns occur. PCPs could benefit from an interface to identify when something is causing a delay in specialty care. PCPs have created workarounds, including lists on paper, phones, and computers, to track patients with major health concerns. These workarounds are increasing PCP workloads, which are already burdensome. Participant agreed that an indicator of discontinued or cancelled referral requests was greatly needed, but current technology did not enable this type of situation awareness. 
Related to reviewing referral notes, information needs seemed to be simple. However, providers experienced significant frustration from lack of consistency in the location of the information and timeliness of information. In the interviews, it was clear that the communication loop between referrer and consultant is often not completed. Despite HIT and procedures intended to support this type of information transfer, referring PCPs indicated that they often do not receive feedback from specialists in a timely manner, especially from external referrals. External referrals would require referring PCPs to log into another system. It is not surprising that this is a "sore point". Information exchange and communication regarding external referrals has been described in existing literature. Although advancements and utilization of health information exchange software to share patient information across different organizations is increasing, gaps in information and communication remain [24]. In our interviews, PCPs reported that the system to view external information was neither usable nor integrated into the EHR. This lack of usability and integration has led to a low adoption of technology to view external information $[25,26]$.

Problems with HIT can disrupt the delivery of care and increase the likelihood of unforeseen errors that affect the quality of care and patient safety [6]. The tabular EHR displays and multiple-system information display, access, and interaction do not provide adequate situational awareness for PCPs' decision-making. In 2015, a study of 11 EHR systems noted that conducting contextually rich studies of clinical workflow, recruiting participants for usability studies, and having support from leadership within the vendor organization were challenges to implementing user-centered design practices[27]. In 2018, a study of 5 major EHR vendors demonstrated EHR usability issues and their potential contribution to patient harm[28]. According to Howe (2018), usability issues related to interoperability, alerting, information availability, data entry, visual display, system automation and defaults, and workflow support created clinical process issues related to documentation, order placement, medication administration, and review of results[28]. Consistent with these issues, our study identified and discussed challenges related to the EHR interactions (e.g. interoperability, data entry/forms, information availability) and PCPs' tasks (e.g. order placement, consultation tracking, review of results) during the referral process.

The results from the hierarchy task analysis provide important guidance for tailoring user interfaces to meet PCPs' information needs and cognitive demands, rather than overwhelming them with a flood of data or missing data [29]. The card sort results demonstrated variability in the level of agreement for specific information needs. Because provider workflows are variable, we expected some degree of 
variability, which accounts for characteristic differences such as providers' clinical experience, EHR's functionality and utility, and provider's expertise with the EHR. In addition to cognitive requirements and workload, these types of characteristics should be considered in a user-centered (re)design of EHRs and health information technology.

\subsection{Limitations and Future Work}

In this study, we focused on referring PCPs, who interact with an EHR to fulfill their information needs. Future studies should consider other types of clinicians who are involved in the tasks highlighted in the goal hierarchy. Specialists, nurses, health technicians, and medical support assistants were mentioned as playing key and supporting roles. Nonetheless, the focus on the referring PCP addresses one of the primary roles in the referral process. Furthermore, clinicians have multiple sources of information that include interacting with other health information technologies and healthcare professionals. Additional insights may be gained in future studies that consider relevant information needs and sources beyond the EHR.

While this study has implications for the (re)design of other healthcare systems, it was conducted within one healthcare system. Of note, the VA is the largest integrated healthcare system in the nation. VA PCPs often have experience across healthcare organizations. Our model was constructed based on referring PCPs' goals, tasks, and decisions as a platform-independent model. Although this study only reports the challenges encountered with the VA's current EHR system, Computerized Patient Record System, it was conducted at multiple sites dispersed across the country which introduced diverse experiences and EHR customizations. Our anecdotal experience suggest that many of the problems noted here are likely to be found during the referral process in other health systems. We advocate future studies to validate our model's generalizability and investigate the extent to which the challenges noted in this study exist in other health systems' referral processes.

This research informs future design efforts to improve EHR systems capability to support decisionmaking during the referral process. Future studies should further analyze the information requirements and needs, with emphasis on situation awareness design and measurement. To design user interfaces that improve situation awareness, the next step would be to classify the information needs according to perception, comprehension, and projection (i.e., levels of situation awareness). These levels will further clarify how the information should be displayed on screens for PCP decision-making. Additional studies could statistically evaluate the priority and relative criticality of information needs across the referral 
process and among a variety of clinicians. Furthermore, future studies could consider other cognitive models that include environmental or organizational factors in the referral decision-making process. For example, the recognition-primed decision model could be used to characterize primary care decision making and generate evidence of recognition-primed versus analytic decisions in the context of the referral process.

\section{Conclusions}

Cognitive demand for referring PCPs is high throughout the referral process. PCPs have to search, identify, compose, track, and integrate information across multiple screens, systems, and people. These tasks are important to establish and maintain effective communication and information transfer with specialists. Existing technologies used in referral and consultation do not appear to support the needed communication, information exchange, or care coordination adequately. This study generated a cognitive framework to identify information needs for referring PCPs. It clarifies needs for each task in the referral process. While workflows and information needs may vary across PCPs, this research shows agreement among types of information needed, highlighting a convergence for general referral processes.

Our cognitive framework informs the design of user-centered, information-focused user interfaces to support referring PCPs throughout the referral process. Prioritizing identification of information needs and how information is displayed would address current issues related to information overload, information scatter, and missing information. With these results and the application of human factors engineering, information requirements can be developed to guide the development of user interfaces that better support the referral process and its related communication, information exchange, and care coordination.

\section{Summary Table:}

What was known:

- Poor care coordination of specialty referrals can increase delays in care, physician workload, and patient safety risks.

- Successful coordination of referrals requires effective, timely information sharing to facilitate communication and transfer of patient care responsibilities.

What this study added to our knowledge:

- We define four major decision points throughout the referral process where cognitive demand for referring PCPs peaks. 
- Characterizations of physician experiences identify salient challenges in communication, information exchange, and care coordination.

- Our cognitive framework informs the design of user-centered, information-focused user interfaces to support referring PCPs throughout the referral process.

\section{Acknowledgements}

Special thanks to Rachel Gruber and Himalaya Patel for their assistance with the coordination, review, and submission of this publication.

Role of the funding source: The research reported here was supported by a VA HSR\&D InvestigatorInitiated Research Grant (IIR 12-102, M. Weiner), the Veterans Health Administration, Office of Informatics and Information Governance (10P2), Human Factors Engineering (IPA PO\# 776C63044), and by the U.S. Department of Veterans Affairs, Veterans Health Administration, Health Services Research and Development Service (CIN 13-416). Views expressed in this article are those of the authors and do not necessarily represent the views of the Department of Veterans Affairs or the U.S. Government. The funding sources had no involvement in the study design; in the collection, analysis, and interpretation of data; in the writing of the report; or in the decision to submit the article for publication.

Conflict of interest statement: The authors report no conflicts of interest

\section{Author Contributions:}

Conception and design: AS, JH

Analysis and interpretation of the data: AS, LM, JD

Drafting of the article: AS, LM, JD, AM, MW, JH, HA

Critical revision of the article for important intellectual content: AS, LM, JD, AM, MW, JH

Final approval of the article: AS, LM, JD, AM, MW, JH, HA

Provision of study materials or patients: AS, LM, JD, AM, HA 
Statistical expertise: -

Administrative, technical, or logistic support: HA, JH, AM

Collection and assembly of data: LA, JD, HA, AM 


\section{References}

[1] GAO, VA Health Care: Actions Needed to Improve Newly Enrolled Veterans' Access to Primary Care, 2016.

[2] GAO, VA Health Care: Management and Oversight of Consult Process Need Improvement to Help Ensure Veterans Receive Timely Outpatient Specialty Care, in: U.S.G.A. Office (Ed.), 2014.

[3] J. Hoffman, Malpractice risks in communication failures 2015 Annual benchmarking report, 2015, pp. 24.

[4] J.N. Olayiwola, D. Anderson, N. Jepeal, R. Aseltine, C. Pickett, J. Yan, I. Zlateva, Electronic Consultations to Improve the Primary Care-Specialty Care Interface for Cardiology in the Medically Underserved: A Cluster-Randomized Controlled Trial, 14 (2016) 133-140.

[5] C.B. Forrest, A typology of specialists' clinical roles, Archives of Internal Medicine, 169 (2009) 1062.

[6] P. Ranade-Kharkar, C. Weir, C. Norlin, S.A. Collins, L.A. Scarton, G.B. Baker, D. Borbolla, V. Taliercio, G. Del Fiol, Information needs of physicians, care coordinators, and families to support care coordination of children and youth with special health care needs (CYSHCN), Journal of the American Medical Informatics Association, 24 (2017) 933-941.

[7] J.J. Saleem, A.L. Russ, A. Neddo, P.T. Blades, B.N. Doebbeling, B.H. Foresman, Paper persistence, workarounds, and communication breakdowns in computerized consultation management, Int J Med Inform, 80 (2011) 466-479.

[8] D.F. Sittig, J.S. Ash, H. Singh, The SAFER guides: empowering organizations to improve the safety and effectiveness of electronic health records, The American journal of managed care, 20 (2014) 418.

[9] D.F. Sittig, D.R. Murphy, M.W. Smith, E. Russo, A. Wright, H. Singh, Graphical display of diagnostic test results in electronic health Records: a comparison of 8 systems, Journal of the American Medical Informatics Association, 22 (2015) 900-904.

[10] L. Militello, A. Savoy, B. Porter, M. Flanagan, J. Wu, J. Adams, S. Rehman, H. Abbaszadegan, M. Weiner, Hidden complexities in information flow between primary and specialty care clinics, 2018. [11] A. Savoy, H. Patel, M.E. Flanagan, M. Weiner, A.L. Russ, Systematic heuristic evaluation of computerized consultation order templates: Clinicians' and human factors engineers' perspectives, Journal of medical systems, 41 (2017) 1-9.

[12] A. Savoy, L.G. Militello, H. Patel, M.E. Flanagan, A.L. Russ, J.K. Daggy, M. Weiner, J.J.J.J.o.b.i. Saleem, A cognitive systems engineering design approach to improve the usability of electronic order forms for medical consultation, 85 (2018) 138-148.

[13] A. Savoy, H. Patel, M.E. Flanagan, Comparison of Two Electronic Order Forms for Medical Consultation: Think-Aloud Usability Assessment With Referring Clinicians, (2017).

[14] D.L. Phipps, G.H. Meakin, P.C.J.A.e. Beatty, Extending hierarchical task analysis to identify cognitive demands and information design requirements, 42 (2011) 741-748.

[15] N.A. Stanton, Hierarchical task analysis: Developments, applications, and extensions, Applied ergonomics, 37 (2006) 55-79.

[16] B. Crandall, Working minds a practitioner's guide to cognitive task analysis, in: G.A. Klein, R.R. Hoffman (Eds.), MIT Press, Cambridge, Mass. :, 2006.

[17] M.B. Miles, A.M. Huberman, M.A. Huberman, M. Huberman, Qualitative data analysis: An expanded sourcebook, sage1994.

[18] K. Holtzblatt, S.J.P.d.P. Jones, practices, Contextual inquiry: A participatory technique for system design, (1993) 177-210. 
[19] K. Holtzblatt, H. Beyer, Contextual design: Design for life, Morgan Kaufmann2016.

[20] S.K. Card, The psychology of human-computer interaction, CRC Press2017.

[21] A.R. Lyon, J.K. Wasse, K. Ludwig, M. Zachry, E.J. Bruns, J. Unützer, E.J.A. McCauley, P.i.M. Health, M.H.S. Research, The contextualized technology adaptation process (CTAP): Optimizing health information technology to improve mental health systems, 43 (2016) 394-409.

[22] A. Castleberry, NVivo 10 [software program]. Version 10. QSR International; 2012, American Journal of Pharmaceutical Education, 78 (2014) 25.

[23] H. Singh, A. Esquivel, D.F. Sittig, D. Murphy, H. Kadiyala, R. Schiesser, D. Espadas, L.A. Petersen, Follow-up actions on electronic referral communication in a multispecialty outpatient setting, Journal of General Internal Medicine, 26 (2010) 64-69.

[24] J.R. Vest, L.D. Gamm, Health information exchange: persistent challenges and new strategies, J Am Med Inform Assoc, 17 (2010) 288-294.

[25] M. Reisman, EHRs: The Challenge of Making Electronic Data Usable and Interoperable, P \& T : a peer-reviewed journal for formulary management, 42 (2017) 572-575.

[26] S. Ajami, T. Bagheri-Tadi, Barriers for Adopting Electronic Health Records (EHRs) by Physicians, Acta informatica medica : AIM : journal of the Society for Medical Informatics of Bosnia \& Herzegovina : casopis Drustva za medicinsku informatiku BiH, 21 (2013) 129-134.

[27] A.Z. Hettinger, R.M. Ratwani, R.J. Fairbanks, N.C. Benda, Electronic health record usability: analysis of the user-centered design processes of eleven electronic health record vendors, Journal of the American Medical Informatics Association, 22 (2015) 1179-1182.

[28] J.L. Howe, K.T. Adams, A.Z. Hettinger, R.M. Ratwani, Electronic Health Record Usability Issues and Potential Contribution to Patient HarmEHR Usability Issues and Potential Contribution to Patient HarmLetters, JAMA, 319 (2018) 1276-1278.

[29] C.A. Bolstad, J.M. Riley, D.G. Jones, M.R. Endsley, Using Goal Directed Task Analysis with Army Brigade Officer Teams, Proceedings of the Human Factors and Ergonomics Society Annual Meeting, 46 (2002) 472-476. 


\section{Figure Legend}

Figure 1. Hierarchical Task Analysis (HTA) Methods Overview

\begin{tabular}{|c|c|c|c|}
\hline Data Collection & Analves & \multicolumn{2}{|c|}{ Models } \\
\hline Cognitive interviews: & $\begin{array}{l}\text { Hierarchical Task Analysis } \\
\qquad(\text { HTA) }\end{array}$ & PrelminaryGoal Hisrarchy. & \\
\hline Conteatual inquiry & $\begin{array}{c}\text { HTA } \\
\text { Qualtative Analysis }\end{array}$ & Ravised Goal Hierarchy & 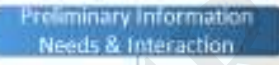 \\
\hline CardSort & $\begin{array}{l}\text { Qualitative Analysis } \\
\text { HTA Tabular form Extension }\end{array}$ & Final Goal Hierarchy & $\begin{array}{c}\text { Final information weeds } 8 \\
\text { Intoraction }\end{array}$ \\
\hline
\end{tabular}

Figure 2. Foundational Questions for Knowledge Elicitation
Questions for the PCPs included:
1. Could you walk me through a time when a consultation went well?
2. Could you walk me through a time when a consultation did not go well?
3. Do your consults ever get cancelled? Why?
4. Could you describe how communication with specialists works with the EHR?
5. Are there ways that you communicate with specialist outside of the EHR?
6. Please describe EHR functionalities that are facilitators and barriers during the consultation process. 
Figure 3. Primary Care Providers' Goal Hierarchy for the Referral Process

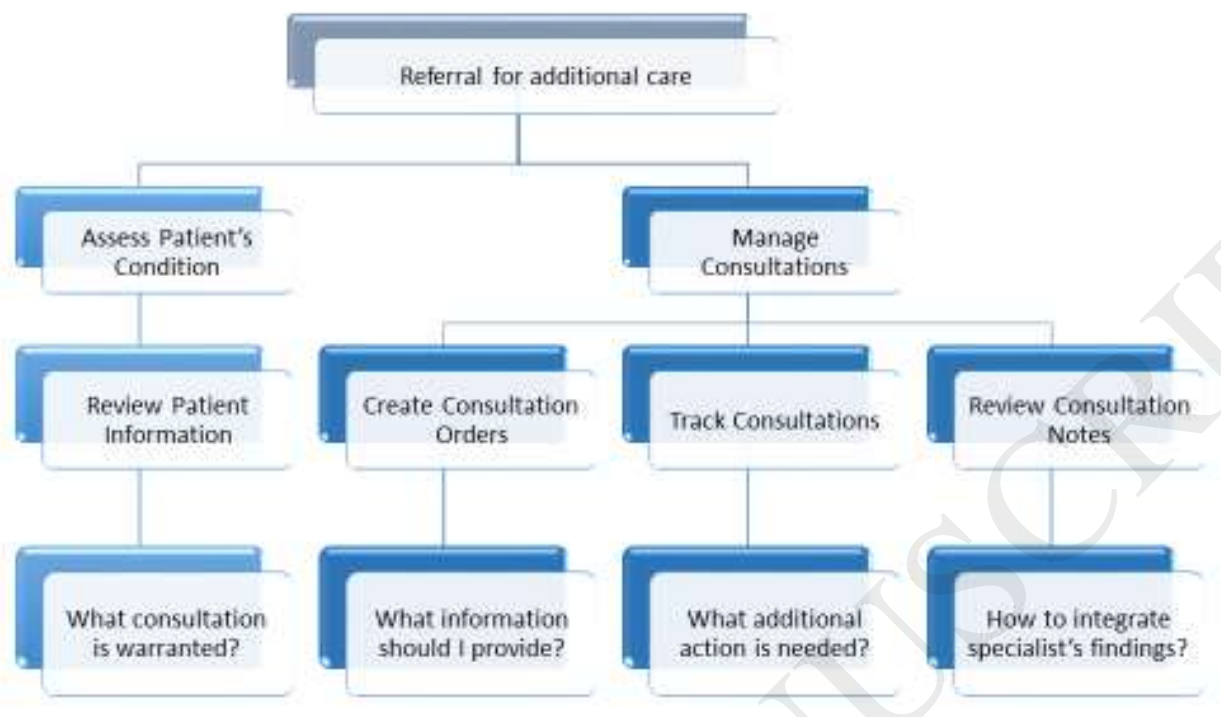

